\title{
Tools for pressure core sub-coring and pore-scale micro-CT (computed tomography) scans
}

\author{
Yongkoo Seol ${ }^{1}$, Liang Lei ${ }^{1, \text { a }}$, Karl Jarvis ${ }^{1,2}$, Daniel Hill ${ }^{1,3}$, Jeong-Hoon Choi ${ }^{1,2}$, Taehyung Park ${ }^{1}$, \\ Xuerui Gai ${ }^{1}$, Greg Wunderlich ${ }^{4}$, Bill Grey ${ }^{4}$, and Chris McArdle ${ }^{4}$ \\ ${ }^{1}$ National Energy Technology Laboratory, U.S. Department of Energy, Morgantown, West Virginia 26507, USA \\ ${ }^{2}$ Leidos Research Support Team, Morgantown, West Virginia 26507, USA \\ ${ }^{3}$ AMENTUN, Morgantown, West Virginia 26507, USA \\ ${ }^{4}$ AMENTUM, Greenwood Village, Colorado 80111, USA \\ ${ }^{a}$ now at: School of Engineering, Westlake University, Hangzhou, Zhejiang 310024, China
}

Correspondence: Liang Lei (leiliang@westlake.edu.cn)

Received: 15 August 2020 - Revised: 11 January 2021 - Accepted: 13 January 2021 - Published: 26 April 2021

\begin{abstract}
The pore habits of gas hydrate in natural sediment matrices provide essential clues for understanding physical (mechanical, thermal, hydraulic, and electrical) properties of hydrate-bearing sediments, yet there are no tools that can directly visualize the pore habits of natural gas hydrate other than indirect interpretation based on core-scale or field-scale observations. A significant challenge is to obtain a mini-core from pressure cores retrieved from natural reservoirs for high-resolution micro-CT (computed tomography) scans while maintaining pressure and temperature conditions required for stability of gas hydrate during all operational steps including manipulation, cutting, transferring, sub-coring and CT scanning. We present a new set of tools for pore-scale micro-CT imaging of natural hydrate-bearing sediments while maintaining pressure and temperature control. The tests with laboratory-prepared cores and pressure cores successfully demonstrate the capability of this set of tools to subsample a mini-core from pressure cores, transfer the mini-core to an X-ray transparent core holder, and conduct micro-CT scans. Successfully obtained CT images prove the functionality of this set of tools.
\end{abstract}

\section{Introduction}

Physical properties of deep marine gas hydrate-bearing sediments draw growing attention as they are a critical input for predicting energy extraction efficiency, seafloor settlement and wellbore stability. Due to high pressure in typical energy-enriched environments, gas bubbles as well as the dissolved gas in the fluid can expand drastically when depressurized. Gas hydrate in solid crystalline form can release gas with $\sim 164$ times the hydrate volume under standard conditions (Boswell and Collett, 2011). High pressure and low temperature are required to maintain the stability of gas hydrate (Makogon, 1997; Sloan and Koh, 2007). If the fluid pressure is not maintained during the coring process, the gas contained in the sediment pores, in the form of free gas, dissolved gas or solid gas hydrate, could expand drastically and potentially destroy the initial fabric of the sediments. Physi- cal properties such as permeability and mechanical strength are directly affected by the sediment fabric. Maintaining the original sediment fabric, therefore, is of critical importance for the characterization of these sediments. Additionally, the study of hydrate-bearing sediments requires the preservation of hydrate and its pore habits in natural environments, which is of special interest because gas hydrate as a solid is a part of the sediment skeleton that affects both the mechanical and hydrological behaviors of the sediments (Boswell, 2009; Boswell and Collett, 2011).

A pressure-coring technique, which preserves the fluid pressure of the sample during the coring process (Amann et al., 1997; Dickens et al., 2003; Kvenvolden et al., 1983; Pettigrew, 1992; Qin et al., 2005; Dai et al., 2012; Schultheiss et al., 2009), is maturing rapidly with gas hydrate exploration activities in Japan, South Korea, India, China, and recently the US (Collett et al., 2019; Flemings et al., 2018; Ya- 
mamoto, 2015; Yun et al., 2011; Zhang et al., 2014). The physical properties of pressure cores have been measured at core scale with specially developed tools (Fang et al., 2020; Priest et al., 2019; Santamarina et al., 2015; Yoneda et al., 2018; Yoneda et al., 2019; Yun et al., 2011), covering mechanical, thermal, hydraulic and electric properties. Interpretations of the results are largely based on idealized pore habits: grain coating, cementing and pore filling (Dai et al., 2012; Waite et al., 2009; Yun et al., 2007). Defining the real distribution and morphology of hydrate within the sediment matrix is critical for understanding the sediment physical properties and resulting interpretations. However, there are no tools that allow for direct visualization of pore-scale behaviors of natural hydrate-bearing sediments to date.

A micro-CT (computed tomography) technique utilizing phase contrast has been developed to obtain the pore-scale structure of laboratory-synthesized methane hydrate-bearing sediments (Lei et al., 2018), but the core size must be less than $10 \mathrm{~mm}$ in order to achieve high-resolution scans. The diameter of whole-round pressure core samples from currently available pressure core drilling tools is $>50 \mathrm{~mm}$ (Schultheiss et al., 2009). Therefore, a toolset is essential to enable the retrieval of a mini-core from a larger pressure core while maintaining the pressure and temperature of the hydrate-bearing sediments under in situ conditions during the whole process. Sub-coring tools have been developed for this specific purpose (Jin et al., 2014; Schultheiss et al., 2009; Parkes et al., 2009), but they have not been applied to pressure cores for pore-scale micro-CT scanning.

This work presents a set of tools that can subsample a mini-core from pressure cores and transfer it into an X-ray transparent core holder under in situ conditions. The minicore is then scanned with a micro-CT scanner with a resolution of $2 \mu \mathrm{m}$. Mini-core sub-coring and transferring processes are presented together with basic operations on full-size pressure cores including grabbing, manipulation, and cutting. Details on CT scan configuration and the X-ray transparent core holder are covered in Lei et al. (2018) and Seol et al. (2019).

\section{Concept of design and operation procedure}

This section describes the concept design and operational sequence to achieve the desired functionality. The requirement is to drill a mini-core ( $9.5 \mathrm{~mm}$ in diameter) out of the original pressure core ( $50 \mathrm{~mm}$ in diameter) and transfer the mini-core into the attached micro-CT scanning assembly. Temperature is maintained inside an environmental chamber at $6 \pm 0.5^{\circ} \mathrm{C}$ where drilling and transfer of the mini-core occur. The fluid pressure is maintained by ISCO high-pressure syringe pumps at $24.1 \mathrm{MPa}(3500 \mathrm{psi})$. The pressure rating of this system is $34.5 \mathrm{MPa}(5000 \mathrm{psi})$. Due to the pressures required for such a process, this set of tools is designed to ASME B31.3 and ASME BVPC Section VIII, Div 1, where required. The mini- core together with its hosting micro-CT scanning assembly is then covered in thermal insulation and relocated to the microCT scanner for 3D pore-scale scanning. Figure 1 shows the key components that enable this capability: $(a, b)$ the manipulator and cutter used for general pressure core manipulation, temporary storage and cutting; (c, d) the sub-coring tool to drill a mini-core; and (e,f) the sub-coring chamber where the mini-core drilling occurs and the attached micro-CT scanning assembly to receive and scan the mini-core with X-ray CT. The functions of each component will be described in the following sections.

\subsection{General operations for pressure cores}

The pressure core is retrieved from the Gulf of Mexico during the University of Texas (UT) Hydrate Pressure Coring Expedition 1 (UT-GOM2-1), at the well in Green Canyon Block 955 (GC 955). The core is from the hydrate reservoir between 425 and $428 \mathrm{~m}$ below the sea floor, and the reservoir is composed of fine sands interbedded with clays according to the LWD log characterization (Fang et al., 2020; Boswell et al., 2012).

Pressure cores are initially held under pressure in specially designed transport chambers. A series of operations are required to manipulate and cut the pressure core into proper lengths before they get transferred into various function modules, such as a cutter or a CT scanning chamber, for specialized characterization. There is literature available (Santamarina et al., 2012; Schultheiss et al., 2009) describing the general concept of pressure core manipulation. Figure 2 shows the cross-section view of a typical pressure core transfer process: (a) pressurize the temporary storage chamber and the space between two ball valves with deionized water to the same pressure as that in the transportation chamber; (b) open the two ball valves and use the grabber to grab the core sleeve in the function module (transportation chamber as an example here); note that the friction between the pressure core and the sleeve binds them together; (c) transfer the pressure core to the temporary storage chamber by retrieving the grabber and close the left ball valve. The key component of pressure core handling is the manipulator module (Fig. 1a and b). It consists of a manipulator that pushes or pulls pressure cores inside core sleeves with a sleeve grabber, a temporary storage chamber, and a ball valve (components A, B and C in Fig. 2). Two viewports are installed on the temporary storage chamber to visually check the position and quality of the pressure core. The pressure core is retrieved from a function module with the procedure displayed in Fig. 2. A similar approach is used to insert the pressure core into other function modules. Note that the function module could be a cutter (Fig. 1a), storage chamber, sub-coring chamber (Fig. 1e and f), or any other stand-alone modules built for specific purposes. 

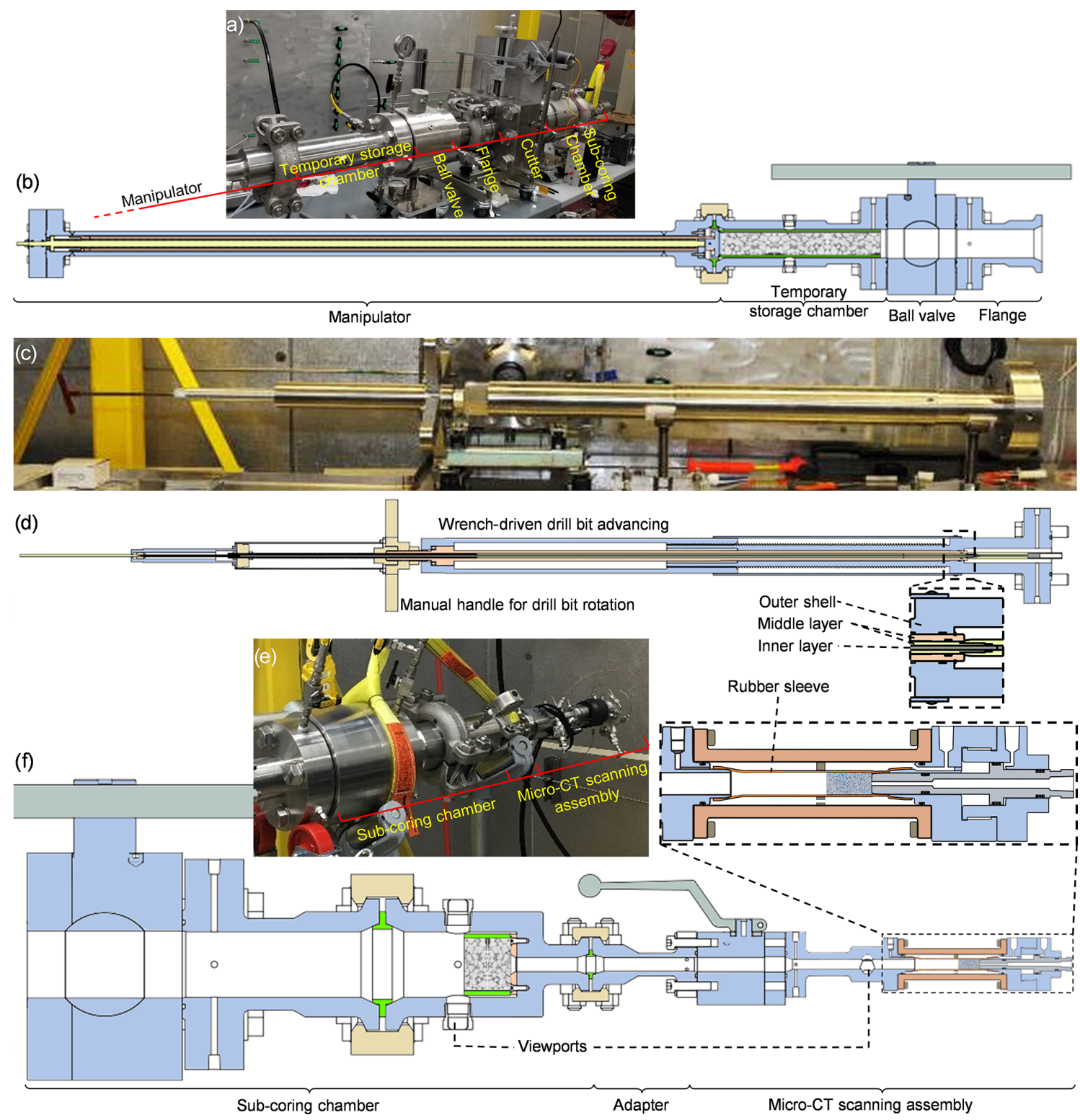

Figure 1. Pressure core Characterization and X-ray visualization Tool (PCXT) components. (a) Manipulator module and automated cutter, (b) section view of the manipulator module, (c) sub-coring tool, (d) section view of the sub-coring tool, (e) sub-coring chamber and microCT scanning assembly that includes a small ball valve, core holder adapter and beryllium core holder, and (f) section view of the sub-coring chamber and micro-CT scanning assembly.

\subsection{Pre-operations before sub-coring}

Core-scale CT scans that provide the overview of the whole core could help verify the status and quality of the pressure core before any further operation, since the pressure core degrades during transportation and long-term storage, due to the lack of effective stress-caused core expansion and hydrate dissolution into surrounding water (Dai and Santamarina, 2014; Jang et al., 2019a). A pressure core initially stored in a transportation chamber is transferred into the CT scanning chamber for the core-scale overview scan first. After the core-scale CT scan, the pressure core is transferred from the CT scan chamber into the manipulator. Then the pressure core is pushed into the automated cutter, placed at a predetermined location, cut into appropriate lengths, and pushed further into the position for the sub-coring process (Fig. 3). The residual pressure core is pulled back to the temporary storage chamber for other purposes.

\subsection{Sub-coring and mini-core transfer}

Once the sub-coring chamber is detached from the cutting assembly and attached to the sub-coring tool, the cut pressure 


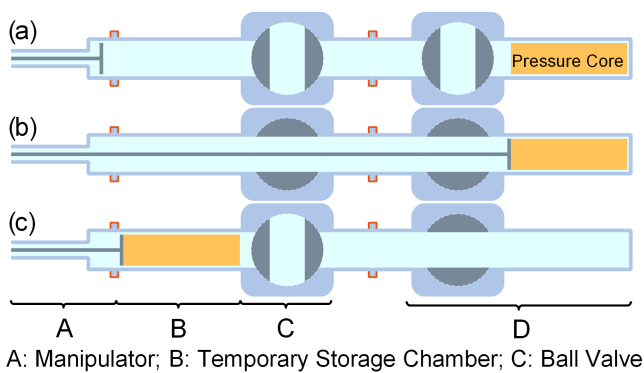

A: Manipulator; B: Temporary Storage Chamber; C: Ball Valve; D: Transportation Chamber or other Function Modules.

Figure 2. General operations for pressure core manipulation (modified from Santamarina et al., 2012). The manipulator module includes manipulator, temporary storage chamber and ball valve.

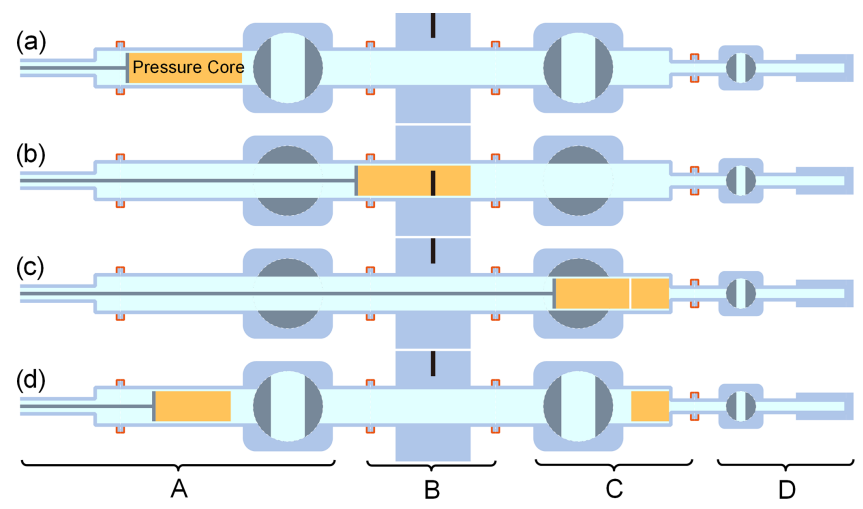

A: Manipulator Module; B: Cutter; C: Sub-coring Chamber; D: Micro-CT Scanning Assembly.

Figure 3. Pressure cores being cut to appropriate lengths and transferred into the sub-coring chamber. (a) Equilibrate the pressure in all the components; (b) push the pressure core to the predetermined position and cut it; (c) push the pressure core to the sub-coring chamber; (d) retrieve the remaining pressure core into the temporary storage chamber.

core inside the sub-coring chamber is ready for sub-coring (Fig. 4a). The sub-coring tool consists of three main layers: the outer shell that holds the pressure, the middle layer and connected drill bit to drill a mini-core from the pressure core, and the inner layer that pushes the drilled mini-core into the micro-CT scanning assembly. The standard drill bit is designed to cut hard cores and made of 316 stainless steel, with an ID of $9.35 \mathrm{~mm}(0.368 \mathrm{in})$, OD of $12.7 \mathrm{~mm}(0.5 \mathrm{in})$ and depth of $163.8 \mathrm{~mm}$ (6.45 in). The OD of the drill bit tip (63.5 $\mathrm{mm}$ or $2.5 \mathrm{in}$, longer than the expected mini-core) can reduce to eliminate sample disturbance in softer cores, e.g., $10.57 \mathrm{~mm}$ (0.416 in) when pushing through hydrate-bearing pressure cores. Note that the advancing and rotating of the drill bit are independent in this design, driven by specially designed wrenches and manually operated handles (Fig. 1c and d).

The drill bit is first pushed against the core without being rotated, which can also be observed from the viewport on the sides (Fig. 1f). The viewports (Encole LLC, NPT 3/4) are

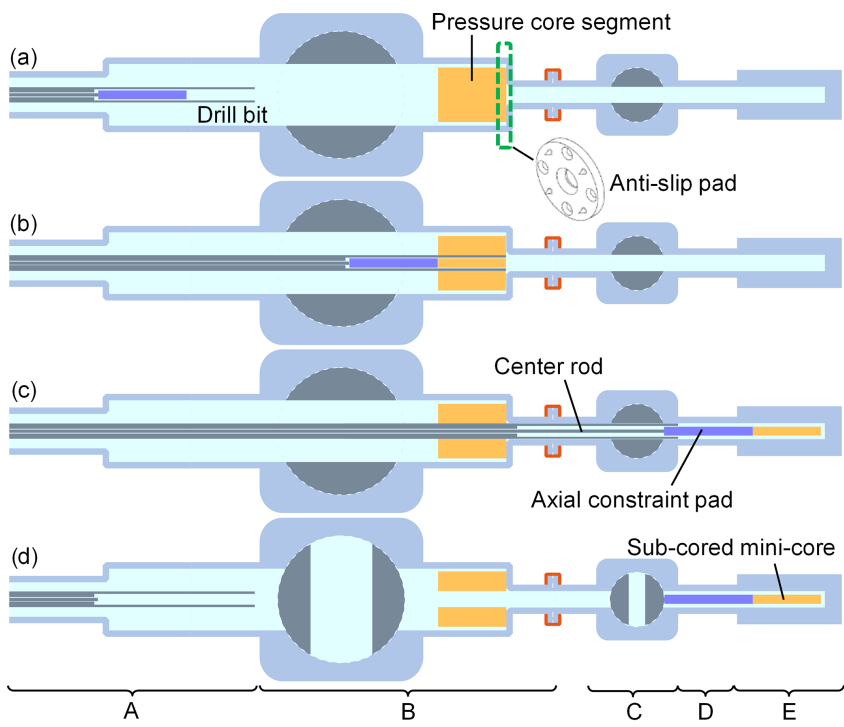

A: Sub-coring Tool; B: Sub-coring Chamber; C: Small Ball Valve; D: Chamber Adapter; E: Beryllium Core Holder.

Figure 4. Sub-coring of cut pressure core and mini-core transfer into micro-CT scanning assembly that includes small ball valve, chamber adapter, and beryllium core holder. (a) Assemble the subcoring components and attach them to the chamber that contains the cut pressure core; (b) open the ball valve and advance and drill through the pressure core; (c) advance the drill bit now containing the mini-core to pass the small ball valve and use the center rod in the inner layer to push the mini-core out of the drill bit towards the end of the beryllium core holder; (d) retract the drill back to its original position. Note the anti-slip pad and its location in the sub-coring chamber (green frame in panel a).

rated up to $6170 \mathrm{psi}$ with the diameter of window $14.0 \mathrm{~mm}$ (0.55 in). There is an anti-slip pad with teeth of sharpened screws in a radial pattern outside the center sampling area penetrating the pressure core and resisting the rotation of the core while drilling. To subsample the pressure core, the rotating and pushing of the drill bit occur simultaneously with different combinations according to the properties of the core. For a hard core such as sandstone, a higher rotation-toadvance ratio is recommended. For soft sediments, the drill bit can be punched through the sediment without rotation. After the drill bit cuts through the core (Fig. 4b), the drill bit continues to advance through the small ball valve with the mini-core in it. Then the center rod pushes the axial constraint pad against the mini-core to send the mini-core to the beryllium core holder (Fig. 4c). The axial constraint pad is left inside the micro-CT scanning assembly to provide axial support for the mini-core during hydrological-mechanical testing, and its length is pre-determined according to the length of the obtained mini-core. Both the center rod and the drill bit are retracted from the small ball valve so that the small ball valve can be closed to secure the pressure inside the micro-CT scanning assembly (Fig. $4 d$ ). The pressure in 


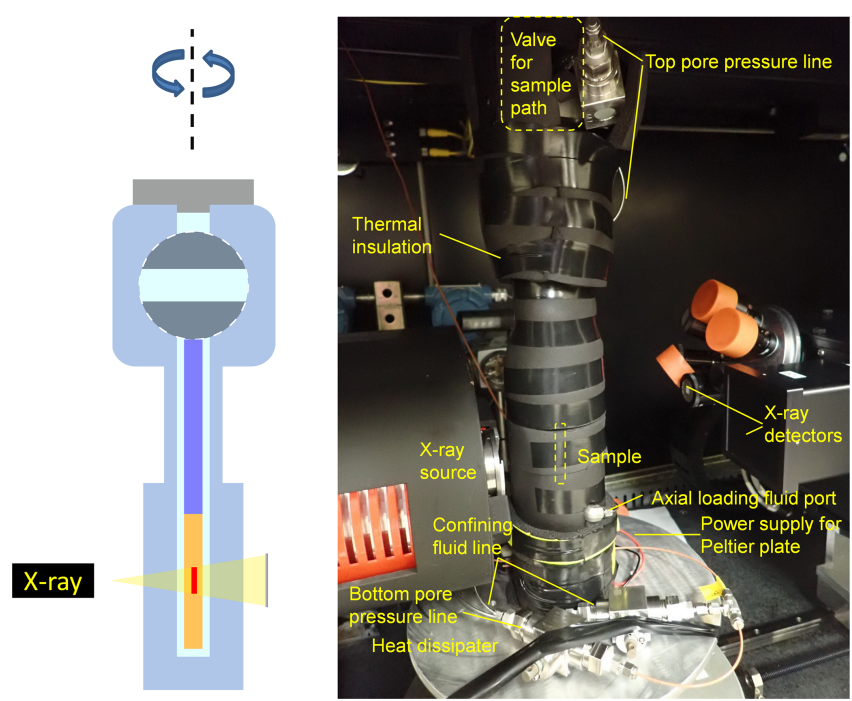

Figure 5. Micro-CT scan of a mini-core under pressure and temperature control.

the sub-coring chamber can be released to dissociate hydrate in the residual pressure core after sub-coring.

The micro-CT scanning assembly is designed to conduct triaxial testing; therefore, the axial support of the mini-core against the pushing pad is critical. Note that the other end of the pushing pad is against the ball of the small ball valve. Therefore, the main body and tail of the pushing pad are made of aluminum and a thin layer of Teflon $(1 / 16$ in or $1.6 \mathrm{~mm}$ ) to increase the stiffness of the pushing pad and prevent scratching of the ball valve surface.

\subsection{Micro-CT scan of mini-cores}

The micro-CT scanning assembly containing the mini-core is detached from the sub-coring tool (Fig. 5a) before it is transferred and mounted on the rotary stage in the microCT scanner (Fig. 5b). Temperature and pressure controls are required to maintain the stability of gas hydrate in the minicore. A Peltier plate is used to control the temperature during CT scanning by transferring heat from the micro-CT scanning chamber and dissipating the heat into the environment. The plate should be turned on at least $1 \mathrm{~h}$ before the minicore transfer so that the rotary stage is pre-chilled to reduce temperature disturbance to the mini-core. One ISCO highpressure syringe pump is connected to both the top pore pressure line and confining fluid line to maintain the fluid pressure. Such a configuration does not apply any effective stress on the core. Micro-CT scans are conducted to obtain 3D structures of the mini-core. Note that the pressure line and power cables for the Peltier plate are all flexible to allow the rotation of the micro-CT scanning assembly during CT scans.

Detailed CT scan configuration and image processing are covered in Lei et al. (2018). Previous results of hydrate

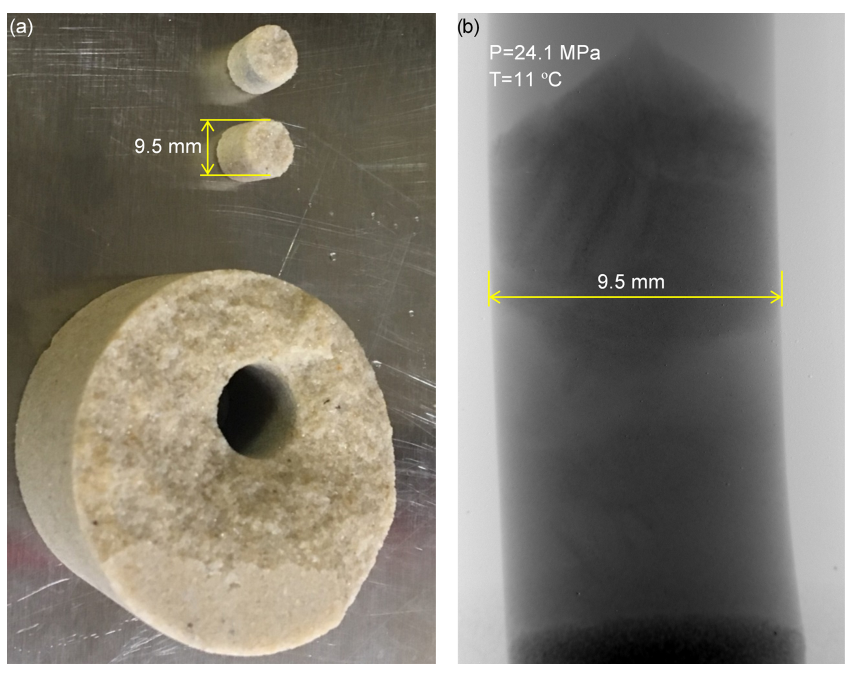

Figure 6. Mini-cores drilled under pressure with this set of tools. (a) Two mini-cores at the top show the capability of this tool to drill through hard sandstones. (b) Mini-core sampled by drilling through a segment of the pressure core.

formation, dissociation and mechanical testing on hydratebearing sediments with laboratory-synthesized cores can be found in Lei and Seol (2020) and Lei et al. (2019a, b).

\section{Results}

\subsection{Sub-coring under pressure}

Sub-coring was successful on both hard sandstone and soft hydrate-bearing sediments under targeted pressure and temperature conditions (Fig. 6), which demonstrates the capability of this set of tools. When drilling through a hard sandstone core, the mini-core broke into two segments during drilling due to shear-induced cracks (Fig. 6a), but this would not affect the micro-CT scanning as a piece of intact sample larger than $3 \mathrm{~mm}^{3}$ is sufficient for a pore-scale micro-CT scan. As for natural hydrate-bearing sediments, the original pressure core degraded during the long-term $(\sim 2$ years $)$ storage and recent manipulations before the sub-coring. Therefore, the drill bit was pushed through the pressure core without any rotation, and the obtained mini-core did not have a perfect column shape (Fig. 6b), but there are intact blocks of hydratebearing sediments in this mini-core, which is large enough to capture the stratigraphic features in the radiographic image, proving its sub-coring capability.

\subsection{Pore-scale imaging of hydrate-bearing sediments}

Figure 7 shows 3D high-resolution micro-CT images of a mini-core from natural gas hydrate-bearing sediments. Three different phases including sediment particles, pore fluid and natural gas hydrate can be identified at pore scale. The voxel size is $2.3 \mu \mathrm{m}$, and sediment particle sizes range from 20 to 


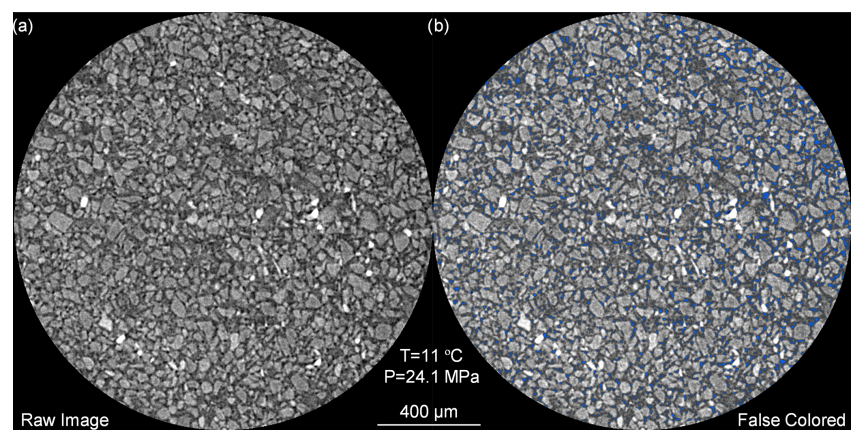

Figure 7. One slice of the 3D image obtained from the micro-CT scan of subsampled natural hydrate-bearing sediments: (a) raw image and (b) false-colored image (hydrate in blue; note that the noise in the raw image is preserved).

$50 \mu \mathrm{m}$. Note that the pore fluid contains some sodium iodide (NaI) salt. The fluid in the core space of the micro-CT scanning chamber contained $7 \mathrm{wt} \%$ of KI initially before the core holder received the mini-core, and this salt concentration is higher than the $5 \mathrm{wt} \%$ in our previous publication (Lei et al., 2018). This 7 wt $\%$ of salt concentration was selected considering fluid mixing with the original pore fluid in the sediment and fluid exchange with the sub-coring chamber filled with deionized water so that the salt concentration of the pore fluid decreases when the system reaches equilibrium. According to the attenuation coefficient analysis based on the effective $\mathrm{X}$-ray spectrum, the brightness of sediment particles, pore fluid and gas hydrate decreases in that order; therefore, the darkest spot in the raw CT image is gas hydrate.

\section{Discussion}

\subsection{Sample disturbance}

Sample disturbance is present in any sampling technique, as the sampling process is inherently associated with different sources of disturbance, including change in effective stress and pore fluid pressure, sample transportation and storage, sample manipulation before testing and so forth (Baligh et al., 1987; Rochelle et al., 1981; Sheng and Carlos, 2014). In the two sub-coring practices with this toolset, there is clear evidence of sample disturbance. When the hard sandstone is used, the drilled mini-core breaks into two segments, as shown in Fig. 6a. This is very likely due to the friction between the drill bit and the mini-core, and the mini-core breaks when the drilling torque exceeds the lateral shear strength of the mini-core. Similar phenomena are often seen in pressure cores (Dai and Santamarina, 2014; Jang et al., 2019b; Fang et al., 2020). Meanwhile, the four teeth on the anti-slip pad damage the surface of the sandstone, but the damage occurs on the outer residual portion of the sample and therefore does not affect the quality of the mini-core taken from the center. As for the soft sediments, the four teeth can easily penetrate the core but do not affect the mini-core quality. When the drill bit is punched through the pressure core, we risk both compression against the core and shear at the side of the mini-core, which is challenging to analyze. Sample disturbance is unavoidable during the coring process. However, for the purpose of visualization of pore-scale hydrate distribution, a small piece of the well-preserved core as seen in both mini-cores in Fig. 6 is sufficient, proving the toolset successfully serves its designated purpose.

\subsection{Toolset features}

This set of tools has several features that facilitate the porescale micro-CT scanning.

1. Small mini-core diameter $(9.5 \mathrm{~mm})$. This core diameter enables high-resolution micro-CT scanning with a resolution of $2 \mu \mathrm{m}$, therefore allowing for natural gas hydrate identification in pore sizes of $20 \mu \mathrm{m}$.

2. Applicable on a wide range of cores. As demonstrated, this tool can subsample mini-cores from both hard and soft cores.

3. Simple and robust core transfer mechanism. The drilling and pushing of the mini-core with this set of tools are along a straight line and only involve the drill bit advancing to deliver the mini-core to the micro-CT scanning assembly.

4. Manual handles in the drilling process. Manual controls on drill rotation and advancement during the subcoring process allow operators to get a direct sense of stress and resistance, thus reducing the likelihood of damage/breakage of the mini-core and original pressure core.

5. Anti-slip pad during sub-coring. The teeth sticking into the pressure core during the drilling process can fix the position of the original pressure core while the drill bit rotates. This approach utilizes the compression between the drill bit and the core and therefore requires no additional pressure core-grabbing mechanism.

6. No additional cutting on the mini-core is required after the drilling process when compared with the tools reported in Parkes et al. (2009).

7. Drilling through the center of the pressure core. An alternative strategy is to drill through the side of the pressure core, which involves drilling through the plastic core sleeve outside the pressure core. There would be a piece of plastic at the end of the mini-core, which prevents axial permeability measurements. Furthermore, to conduct a permeability test, the alternative strategy needs a mechanism to remove the plastic liner from the mini-core end. 
8. Precise control of the mini-core position after core transfer. All the other existing techniques simply push the mini-core into the next testing chamber (Jin et al., 2014; Parkes et al., 2009; Schultheiss et al., 2009), therefore not having control of the mini-core position. The procedure in this study pushes the mini-core into the rubber sleeve which is at the center of the micro-CT scanning assembly.

9. Permeability and mechanical testing of the mini-core are achievable. The micro-CT scanning assembly has a rubber sleeve (Fig. 1f) separating the mini-core and confining fluid to enable the application of lateral confining pressure and a functional end piece that can hydraulically drive a piston to apply axial pressure. Influent and effluent ports allow for flowing fluid through the minicore (further details in Seol et al., 2019). This permits hydrological and mechanical testing of the mini-core, although these tests were not conducted in this study due to the quality of the degraded pressure core.

\subsection{Potential applications}

Direct application. Gas hydrate in nature contains a large amount of natural gas (Boswell and Collett, 2011; Milkov, 2004). Therefore, if commercial gas production is achieved, gas hydrate has the potential to expand the worldwide energy supply. Pore habits within single pores and inter-pore distribution of gas hydrate in sediments reflect formation histories (Lei et al., 2019a); therefore, they can vary in different reservoirs. Major energy consumers and importers such as the US, China, Japan and India are investing extensively in hydrate pressure core research, targeting commercial gas production. This set of tools provides pore-scale insight into the reservoir, which helps us to understand the behavior of hydrate during formation, evolution and production. Physical properties such as permeability, thermal conductivity, mechanical stiffness and strength are highly dependent on the pore habits and distribution of gas hydrate in the sediment matrix. These properties are key input parameters to predict gas production rates and evaluate the cost-benefit ratio through reservoir simulations. Therefore, this sub-coring process and the subsequent micro-CT studies it enables are needed prior to pursuing direct field tests for gas production, especially when offshore operations are involved. Such pore-scale 3D studies help to reveal the interactive nature of hydrate crystals with sediment matrices and their mechanical integrity as well as to acquire reliable quantitative prediction of reservoir productivity.

The tools, used together with the micro-CT scanner, enable monitoring of the multiphase fluid's behaviors in a porous medium as the physicochemical substances change in a chamber. Direct observations of dynamic flow patterns of immiscible fluids, such as oil and brine or $\mathrm{CO}_{2}$ with brine, are attainable through micro-CT analysis in responses to ad- sorption, complexation, and dissolution reactions of the components. Those observations can also be applicable to conventional energy-related fields such as oil recovery, geologic carbon storage and diverse environmental remedial technologies.

Indirect applications. Any applications that require subcoring processes within an isolated environment could use the procedure described here. Since the chamber used in this application could be a barrier for pressure, heat, electrical current or any other physical, chemical or biological changes, the procedure described herein could be used with minor modifications.

\section{Conclusions}

This work presents a series of tools that enable the manipulation, transfer, cutting, sub-coring and CT scanning at both core and pore scale of pressure cores while maintaining pressure and temperature controls. The mini-cores created demonstrate that the sub-coring tool can drill through both hard and soft sediments under pressure and provide adequate samples with intact segments. This set of tools along with the testing procedure allows for the investigation of pore habits of natural gas hydrate within the sediment matrix. Furthermore, this set of tools can be used for other potential operations that require environmental controls throughout all steps of operation.

Data availability. No data sets were used in this article.

Author contributions. YS, KJ, DH, and JHC provided the function and technical requirement and contributed to the original design. GW, BG, and $\mathrm{CM}$ conducted the initial engineering design. LL, YS, KJ, JHC, TP, and XG performed the instrument shakedown, contributed to the design modification, and conducted related experiments. DH modified the engineering design towards the final form. LL prepared the manuscript. All the coauthors edited the manuscript. YS managed the project.

Competing interests. The authors declare that they have no conflict of interest.

Acknowledgements. Liang Lei, Xuerui Gai, and Taehyung Park are supported under an Oak Ridge Institute for Science and Education (ORISE) fellowship granted by NETL. Karl Jarvis (LRST) and Jeong-Hoon Choi (LRST) conducted this work under RSS contract 89243318CFE000003. Pressure core samples were obtained from the UT-GOM2-1 Hydrate Pressure Coring Expedition which was funded by Department of Energy Award DE-FE0023919 and advised by the United States Geological Survey (USGS) and the Bureau of Ocean Energy Management (BOEM) 
Financial support. This research has been supported by the National Energy Technology Laboratory (grant no. 89243318CFE000003) and the U.S. Department of Energy (grant no. DE-FE0023919).

Review statement. This paper was edited by Thomas Wiersberg and reviewed by two anonymous referees.

\section{References}

Amann, H., Hohnberg, H.-J., and Reinelt, R.: HYACE - A novel autoclave coring equipment for systematic offshore gas hydrate sampling, Gas Hydrates: Problems Substance/Resource, Clausthal-Zellerfeld (Harz), Germany, 1997.

Baligh, M. M., Azzouz, A. S., and Chin, C. T.: Disturbances Due to "Ideal" Tube Sampling, J. Geotech. Eng., 113, 739-757, https://doi.org/10.1061/(ASCE)0733-9410(1987)113:7(739), 1987.

Boswell, R.: Is gas hydrate energy within reach?, Science, 325, 957-958, https://doi.org/10.1126/science.1175074, 2009.

Boswell, R. and Collett, T. S.: Current perspectives on gas hydrate resources, Energy Environ. Sci., 4, 1206-1215, https://doi.org/10.1039/C0EE00203H, 2011.

Boswell, R., Frye, M., Shelander, D., Shedd, W., McConnell, D. R., and Cook, A.: Architecture of gas-hydrate-bearing sands from Walker Ridge 313, Green Canyon 955, and Alaminos Canyon 21: Northern deepwater Gulf of Mexico, Mar. Pet. Geol., 34, 134149, https://doi.org/10.1016/j.marpetgeo.2011.08.010, 2012.

Collett, T. S., Kumar, P., Boswell, R., and Waite, W. F.: Preface: Marine gas hydrate reservoir systems along the Eastern Continental Margin of India: Results of the National Gas Hydrate Program Expedition 02, Mar. Pet. Geol., 108, 1-2, https://doi.org/10.1016/j.marpetgeo.2019.03.005, 2019.

Dai, S. and Santamarina, J. C.: Sampling disturbance in hydratebearing sediment pressure cores: NGHP-01 expedition, KrishnaGodavari Basin example, Mar. Pet. Geol., 58, 178-186, https://doi.org/10.1016/j.marpetgeo.2014.07.013, 2014.

Dai, S., Santamarina, J. C., Waite, W. F., and Kneafsey, T. J.: Hydrate morphology: Physical properties of sands with patchy hydrate saturation, J. Geophys. Res.-Sol. Ea., 117, B11205, https://doi.org/10.1029/2012JB009667, 2012.

Dickens, G. R., Schroeder, D. K., Hinrichs, U., and the Leg 201 Scientific Party: The pressure core sampler (PCS) on ODP Leg201: General operations and gas release, in: Proc.ODP, Init. Repts., College Station, TX (Ocean Drilling Program), edited by: D’Hondt, S. L., Jøgensen, B. B., Miller, D. J., et al., 201, 1-22, https://doi.org/10.2973/odp.proc.ir.201.103.2003, 2003.

Fang, Y., Flemings, P. B., Daigle, H., Phillips, S. C., Meazell, P. K., and You, K.: Petrophysical properties of the GC 955 hydrate reservoir inferred from reconstituted sediments: Implications for hydrate formation and production, AAPG Bull., 104, 1997-2028, https://doi.org/10.1306/01062019165, 2020.

Flemings, P. B., Phillips, S. C., Collett, T., Cook, A., Boswell, R., and the UT-GOM2-1 Expedition Scientists: UT-GOM2-1 Hydrate Pressure Coring Expedition Summary, University of Texas Institute for Geophysics, Austin, TX, USA, 2018.
Jang, J., Waite, W. F., Stern, L. A., Collett, T. S., and Kumar, P.: Physical property characteristics of gas hydrate-bearing reservoir and associated seal sediments collected during NGHP-02 in the Krishna-Godavari Basin, in the offshore of India, Mar. Pet. Geol., 108, 249-271, https://doi.org/10.1016/j.marpetgeo.2018.09.027, 2019a.

Jang, J., Dai, S., Yoneda, J., Waite, W. F., Stern, L. A., Boze, L.-G., Collett, T. S., and Kumar, P.: Pressure core analysis of geomechanical and fluid flow properties of seals associated with gas hydrate-bearing reservoirs in the KrishnaGodavari Basin, offshore India, Mar. Pet. Geol., 108, 537-550, https://doi.org/10.1016/j.marpetgeo.2018.08.015, 2019b.

Jin, Y., Konno, Y., and Nagao, J.: Pressurized subsampling system for pressured gas-hydrate-bearing sediment: Microscale imaging using X-ray computed tomography, Rev. Sci. Instrum., 85, 094502, https://doi.org/10.1063/1.4896354, 2014.

Kvenvolden, K. A., Barnard, L. A., and Cameron, D. H.: Pressure core barrel: Application to the study of gas hydrates, Deep Sea Drilling Project Site 533, Leg 76, Washington, D.C., USA, 367 375, 1983.

Lei, L. and Seol, Y.: Pore-scale investigation of methane hydratebearing sediments under triaxial condition, Geophys. Res. Lett., 47, e2019GL086448, https://doi.org/10.1029/2019GL086448, 2020.

Lei, L., Seol, Y., and Jarvis, K.: Pore-scale visualization of methane hydrate-bearing sediments with micro-CT, Geophys. Res. Lett., 45, 5417-5426, https://doi.org/10.1029/2018GL078507, 2018.

Lei, L., Seol, Y., Choi, J.-H., and Kneafsey, T. J.: Pore habit of methane hydrate and its evolution in sediment matrix - Laboratory visualization with phase-contrast micro-CT, Mar. Pet. Geol., 104, 451-467, https://doi.org/10.1016/j.marpetgeo.2019.04.004, 2019a.

Lei, L., Seol, Y., and Myshakin, E. M.: Methane hydrate film thickening in porous media, Geophys. Res. Lett., 46, 11091-11099, https://doi.org/10.1029/2019GL084450, 2019b.

Makogon, Y. F.: Hydrates of hydrocarbons, Pennwell Books, PennWell Publishing Company, Tulsa, Oklahoma, USA, 1997.

Milkov, A. V.: Global estimates of hydrate-bound gas in marine sediments: how much is really out there?, Earth-Sci. Rev., 66, 183197, https://doi.org/10.1016/j.earscirev.2003.11.002, 2004.

Parkes, R. J., Sellek, G., Webster, G., Martin, D., Anders, E., Weightman, A. J., and Sass, H.: Culturable prokaryotic diversity of deep, gas hydrate sediments: first use of a continuous high-pressure, anaerobic, enrichment and isolation system for subseafloor sediments (DeepIsoBUG), Environ. Microbiol., 11, 3140-3153, https://doi.org/10.1111/j.1462-2920.2009.02018.x, 2009.

Pettigrew, T. L.: Design and operation of a wireline Presure Core Sampler (PCS), Texas A\&M University, College Station, Texas, USA, 1992.

Priest, J. A., Hayley, J. L., Smith, W. E., Schultheiss, P., and Roberts, J.: PCATS triaxial testing: Geomechanical properties of sediments from pressure cores recovered from the Bay of Bengal during expedition NGHP-02, Mar. Pet. Geol., 108, 424-438, https://doi.org/10.1016/j.marpetgeo.2018.07.005, 2019.

Qin, H., Gu, L., Li, S., Zhu, L., and Chen, Y.: Pressure tight piston corer - A new approach on gas hydrate investigation, China Ocean Eng., 19, 121-128, https://doi.org/10.3321/j.issn:08905487.2005.01.011, 2005. 
Rochelle, P. L., Sarrailh, J., Tavenas, F., Roy, M., and Leroueil, S.: Causes of sampling disturbance and design of a new sampler for sensitive soils, Can. Geotech. J., 18, 52-66, https://doi.org/10.1139/t81-006, 1981.

Santamarina, J. C., Dai, S., Jang, J., and Terzariol, M.: Pressure Core Characterization Tools for Hydrate-Bearing Sediments, Sci. Dril., 14, 44-48, https://doi.org/10.2204/iodp.sd.14.06.2012, 2012.

Santamarina, J. C., Dai, S., Terzariol, M., Jang, J., Waite, W. F., Winters, W. J., Nagao, J., Yoneda, J., Konno, Y., Fujii, T., and Suzuki, K.: Hydro-bio-geomechanical properties of hydrate-bearing sediments from Nankai Trough, Mar. Pet. Geol., 66, 434-450, https://doi.org/10.1016/j.marpetgeo.2015.02.033, 2015.

Schultheiss, P., Holland, M., and Humphrey, G.: Wireline Coring and Analysis under Pressure: Recent Use and Future Developments of the HYACINTH System, Sci. Dril., 7, 44-50, https://doi.org/10.2204/iodp.sd.7.07.2009, 2009.

Seol, Y., Lei, L., Choi, J.-H., Jarvis, K., and Hill, D.: Integration of triaxial testing and pore-scale visualization of methane hydrate bearing sediments, Rev. Sci. Instrum., 90, 124504, https://doi.org/10.1063/1.5125445, 2019.

Sheng, D. J. and Carlos, S.: Sampling disturbance in hydratebearing sediment pressure cores: NGHP-01 expedition, KrishnaGodavari Basin example, Mar. Pet. Geol., 58, 178-186, https://doi.org/10.1016/j.marpetgeo.2014.07.013, 2014.

Sloan, E. D. and Koh, C. A.: Clathrate hydrates of natural gases (Third edition), edited by: Speight, J. G., CRC Press, Boca Raton, FL, USA, 752 pp., 2007.

Waite, W. F., Santamarina, J. C., Cortes, D. D., Dugan, B., Espinoza, D. N., Germaine, J., Jang, J., Jung, J. W., Kneafsey, T. J., Shin, H., Soga, K., Winters, W. J., and Yun, T. S.: Physical properties of hydrate-bearing sediments, Rev. Geophys., 47, RG4003, https://doi.org/10.1029/2008RG000279, 2009.
Yamamoto, K.: Overview and introduction: Pressure coresampling and analyses in the 2012-2013 MH21 offshore test of gas production from methane hydrates in the eastern Nankai Trough, Mar. Pet. Geol., 66, 296-309, https://doi.org/10.1016/j.marpetgeo.2015.02.024, 2015.

Yoneda, J., Oshima, M., Kida, M., Kato, A., Konno, Y., Jin, Y., Jang, J., Waite, W. F., Kumar, P., and Tenma, N.: Pressure core based onshore laboratory analysis on mechanical properties of hydrate-bearing sediments recovered during India's National Gas Hydrate Program Expedition (NGHP) 02, Mar. Pet. Geol., 108, 482-501, https://doi.org/10.1016/j.marpetgeo.2018.09.005, 2018.

Yoneda, J., Oshima, M., Kida, M., Kato, A., Konno, Y., Jin, Y., Jang, J., Waite, W. F., Kumar, P., and Tenma, N.: Permeability variation and anisotropy of gas hydratebearing pressure-core sediments recovered from the KrishnaGodavari Basin, offshore India, Mar. Pet. Geol., 108, 524-536, https://doi.org/10.1016/j.marpetgeo.2018.07.006, 2019.

Yun, T. S., Santamarina, J. C., and Ruppel, C.: Mechanical properties of sand, silt, and clay containing tetrahydrofuran hydrate, J. Geophys. Res.-Sol. Ea., 112, B04106, https://doi.org/10.1029/2006JB004484, 2007.

Yun, T. S., Lee, C., Lee, J.-S., Bahk, J. J., and Santamarina, J. C.: A pressure core based characterization of hydrate-bearing sediments in the Ulleung Basin, Sea of Japan (East Sea), J. Geophys. Res.-Sol. Ea., 116, B02204, https://doi.org/10.1029/2010JB007468, 2011.

Zhang, G., Yang, S., Zhang, M., Liang, J., Lu, J., Holland, M., and Schultheiss, P.: GMGS2 expedition investigates rich and complex gas hydrate environment in the South China Sea, Fire in the Ice, 14, 1-5, 2014. 